\title{
Hazar Gölü çevresinde yaşayan Neuroptera (Insecta) faunasının saptanmasi
}

\author{
Nalan KOYUNCU1 ${ }^{1}$, Sadreddin TUSUN ${ }^{2 *}$ \\ ${ }^{1}$ Dicle Üniversitesi Fen Bilimleri Enstitüsü, Diyarbakır \\ ${ }^{2}$ Dicle Üniversitesi, Ziya Gökalp Eğitim Fakültesi, Biyoloji Bölümü, Diyarbakır \\ (ORCID: 0000-0002-3499-2736) (ORCID: 0000-0002-0696-4244)
}

\begin{abstract}
Öz
Elâzığ ili Hazar Gölü çevresinde yaşayan Neuroptera (Insecta) faunasının belirlenmesi amacıyla, 2016-2019 yılları Nisan-Eylül ayları arasında önceden belirlenen 108 lokalitede arazi çalışmaları gerçekleştirilmiştir. Bu çalışma bünyesinde toplanan 296 bireyden; 5 familya 18 cins ve 23 tür tespit edilmiştir. Bu türlerin dağılımı ise: Ascalaphidae familyası, 1 cins 2 tür; Chrysopidae familyası, 4 cins 5 tür; Hemerobiidae familyası, 2 cins 2 tür; Myrmeleontidae familyası, 9 cins 11 tür ve Nemopteridae familyası, 2 cins 3 tür şeklindedir. Teşhis edilen türlerden Ascalaphidae familyasına ait Bubopsis hamata (Klug, 1834), Bubopsis andromache (U. Aspöck, H. Aspöck \& H. Hölzel, 1979); Chrysopidae familyasına ait Chrysopa dubitans (McLachlan, 1887), Italochrysa italica (Rossi, 1790); Myrmeleontidae familyasina ait Euroleon nostras (Geoffroy in fourcroy, 1785), Solter ledereri (Navas, 1912), Distoleon tetragrammicus (Fabricius, 1798), Neuroleon egenus (Navas, 1915) ve Nemopteridae familyasına ait Nemoptera sinuata (Olivier, 1811), Lertha sheppardi (Oliver, 1904) Elâzı̆̆ ili için yeni kayıttır.
\end{abstract}

Anahtar kelimeler: Neuroptera, Hazar gölü, fauna, yeni kayıt, Elâzı̆̆.

\section{Detection of Neuroptera (Insecta) fauna living around Hazar Lake}

\begin{abstract}
In order to determine of the Neuroptera (Insecta) fauna that lives around the Hazar Lake in Elazığ province, the field studies are conducted in 108 prespecified locations in April-September of 2016-2019. In this paper, 5 families, 18 genera and 23 species are identified from collected 296 specimens. The distribution of these species are; Ascalaphidae family, 1 genus - 2 species; Chrysopidae family, 4 genera - 5 species; Hemerobiidae family, 2 genera - 2 species; Myrmeleontidae family, 9 genera - 11 species, and Nemopteridae family, 2 genera - 3 species. Among the identified species, Bubopsis hamata (Klug, 1834), Bubopsis andromache (U. Aspöck, H. Aspöck \& H. Hölzel, 1979) belonging to the Ascalaphidae family; Chrysopa dubitans, Italochrysa italica (Rossi, 1790) of the Chrysopidae family (McLachlan, 1887); Euroleon nostras (Geoffroy in fourcroy, 1785), Solter ledereri (Navas, 1912), Distoleon tetragrammicus (Fabricius, 1798), Neuroleon egenus (Navas, 1915) of Myrmeleontidae family (Geoffroy in fourcroy, 1785) and Nemoptera sinuata (Olivier, 1811), Lertha sheppardi (Oliver, 1904) of the Nemopteridae family is the new record for Elazığ province.
\end{abstract}

Keywords: Neuroptera, Hazar lake, fauna, new record, Elazığ.

\section{Giriş}

Neuroptera takımı holometabol böceklerin en eski gruplarından biridir. Bilinen en eski fosilleri, erken Perm periyoduna aittir [1]. Neuroptera ordosu üyeleri deniz seviyesinden 3000 m'ye kadar olan yüksekliklerde, genellikle kısa boylu, yabani ve kültür bitkileri ile maki ve çit bitkileri üzerinde, meyve, sebze ve çiçek bahçelerinde, şehirlerin içinde ki park ve bahçelerde, iğne yapraklı olan veya yaprağını döken çeşitli ağaç türlerinde bulunurlar. Sadece Osmylidae ve Sisyridae üyeleri kirli olmayan su civarlarındaki otsu formdaki çalılar ve ağaçlar üzerinde ayrıca menfez altlarında bulunurlar. Neuroptera

*Sorumlu yazar: sadreddin.tusun@dicle.edu.tr

Geliş Tarihi: 10.12.2019, Kabul Tarihi: 18.05.2020 
ordusuna ait türler tek bir tür bitki üzerinde bulunabildiği gibi, çeşitli bitkiler üzerinde de bulunabilmektedirler $[2,3]$. Neuroptera takımının üyeleri ekonomik değere sahiptir. Ergin ve larvaları, yumuşak vücutlu ve genellikle zararlı böceklerle beslenirler. Özellikle Chrysopidae, Coniopterygidae ve Hemerobiidae familyalarının bireyleri, tarım bitkileri zararlıları ve örümcekler ile beslenirler. Chrysopidae ve Myrmeleontidae familyalarına ait türlerin çoğu predatör olmakla birlikte, polenlerle beslenen türleri de vardır. Ascalaphidae türleri predatördür ve kelebek, sinek gibi böcekleri avlayarak beslenir. Çoğu türün populasyon yoğunlukları yüksektir ve predatör beslenmelerinden dolayı ekonomik önemleri oldukça fazladır [2, 4].

Türkiye'nin çeşitli bölgelerinde bu takıma özgü pek çok araştırma yürütülmüştür [5-15]. Bu araştırmalar sonucunda Türkiye genelindeki bu takıma ait tür sayısı 300 civarındadır. Ancak Elâzı̆ ilinde Neuroptera takımına ait çalışmalar son derece sınırlı olup İlin hepsini kapsayan ve sadece Neuroptera takımını içeren çalışma tektir [16]. Bu çalışma ve diğer genel çalışmalar neticesinde İlin tür sayıs1 23 civarındadır. Elâzığ iline ait Hazar Gölü çevresinde yürütülen bu araştırma neticesinde, 108 lokaliteden 296 birey toplanmıştır. Toplanan bireylerden; 5 familya 18 cins ve 23 tür tespit edilmiştir. Teşhis edilen türlerden Ascalaphidae familyasına ait Bubopsis hamata (Klug, 1834), Bubopsis andromache (U. Aspöck, H. Aspöck \& H. Hölzel, 1979); Chrysopidae familyasına ait Chrysopa dubitans (McLachlan, 1887), Italochrysa italica (Rossi, 1790); Myrmeleontidae familyasina ait Euroleon nostras (Geoffroy in fourcroy, 1785), Solter ledereri (Navas, 1912), Distoleon tetragrammicus (Fabricius, 1798), Neuroleon egenus (Navas, 1915) ve Nemopteridae familyasina ait Nemoptera sinuata (Olivier, 1811), Lertha sheppardi (Oliver, 1904) Elâzı ğ ili için yeni kayıttır.

\section{Materyal ve Metot}

Araştırma alanı olarak seçilen Hazar Gölü Elazığ'a $22 \mathrm{~km}$ uzakta bulunan bir tektonik göldür. $\mathrm{Bu}$ araştırma alanında önceden belirlenen 108 lokalitede arazi çalışmaları gerçekleştirilmiştir (Şekil 1). Neuropter erginlerinin narin yapılı olmaları sebebiyle, örneklerin toplanması, taşınması ve müze materyali haline getirilmesi aşamalarında son derece özen gösterilmiştir. Ergin örnekleri yakalamadaki numuneleri görmek için ince organze perdelik tülden yapılmış 30-35 cm çaplı atraplar kullanılmıştır. Bazı türlerin yakalanmasında ise Robinson 1şık tuzağı ve bahçe aydınlatmalarında kullanılan 1şıktan yararlanılmıştır. Yakalanan ergin böceklerin dişileri yumurtlamaları için uygun ortama bırakılmıştır. Ayrıca toprakta yakalanan larvalar taşıma kutularına konularak laboratuvar ortamına taşınmıştır. Laboratuvar ortamında larvalar beslenmiş, ergin olana dek larval evreleri gözlemlenmiş ve fotoğraflanmıştır. Doktora tezleri, literatürler ve Neuroptera katalogundan yararlanılarak erginlerin teşhisi yapılmıştır $[3,11,14,17]$.

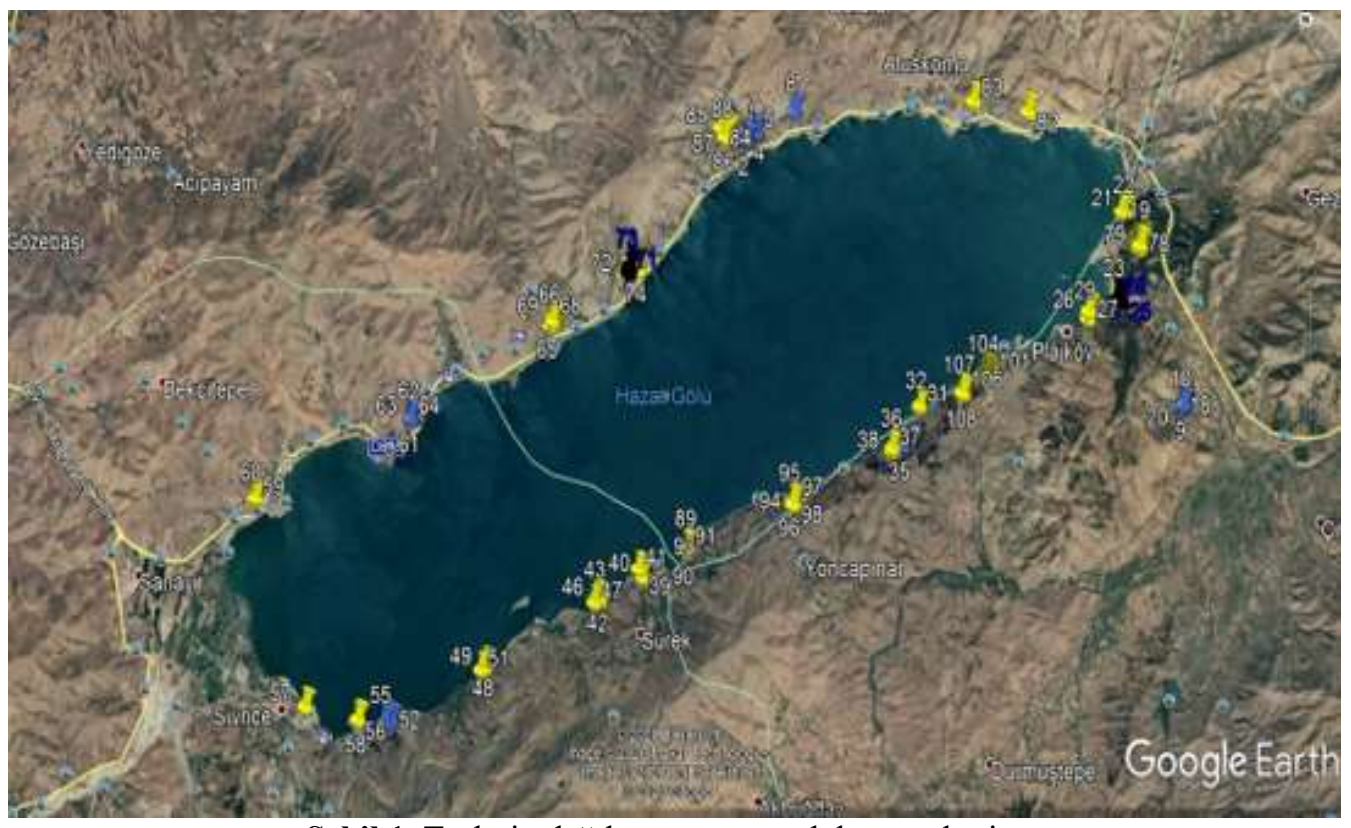

Şekil 1. Türlerin dağılışını gösteren lokasyon haritası 


\section{Bulgular ve Tartışma}

Ascalaphidae Rambur, 1842

Bubopsis McLachan, 1842

Bubopsis hamata Klug, 1834

Tablo 1. Bubopsis hamata'nın çalıșma alanındaki yayılıșı ve yakalanan bireyler

\begin{tabular}{|c|c|c|c|c|}
\hline Kuzey & Doğu & Yükseklik(m) & Erkek & Dişi \\
\hline $38^{\circ} 28^{\prime} 49.88^{\prime \prime}$ & $39^{\circ} 31^{\prime} 17.55^{\prime \prime}$ & 1285 & 4 & 6 \\
\hline $38^{\circ} 28^{\prime} 49.31^{\prime \prime}$ & $39^{\circ} 31^{\prime} 15.69^{\prime \prime}$ & 1297 & 5 & 3 \\
\hline $38^{\circ} 28^{\prime} 49.21^{\prime \prime}$ & $39^{\circ} 31^{\prime} 15.94^{\prime \prime}$ & 1296 & - & 2 \\
\hline $38^{\circ} 29^{\prime} 7.53^{\prime \prime}$ & $39^{\circ} 20^{\prime} 28.29^{\prime \prime}$ & 1281 & 2 & - \\
\hline $38^{\circ} 29^{\prime} 7.19^{\prime \prime}$ & $39^{\circ} 20^{\prime} 27.74^{\prime \prime}$ & 1278 & 1 & 3 \\
\hline
\end{tabular}

*Bu tür Elâzığ ili için yeni kayıttır.

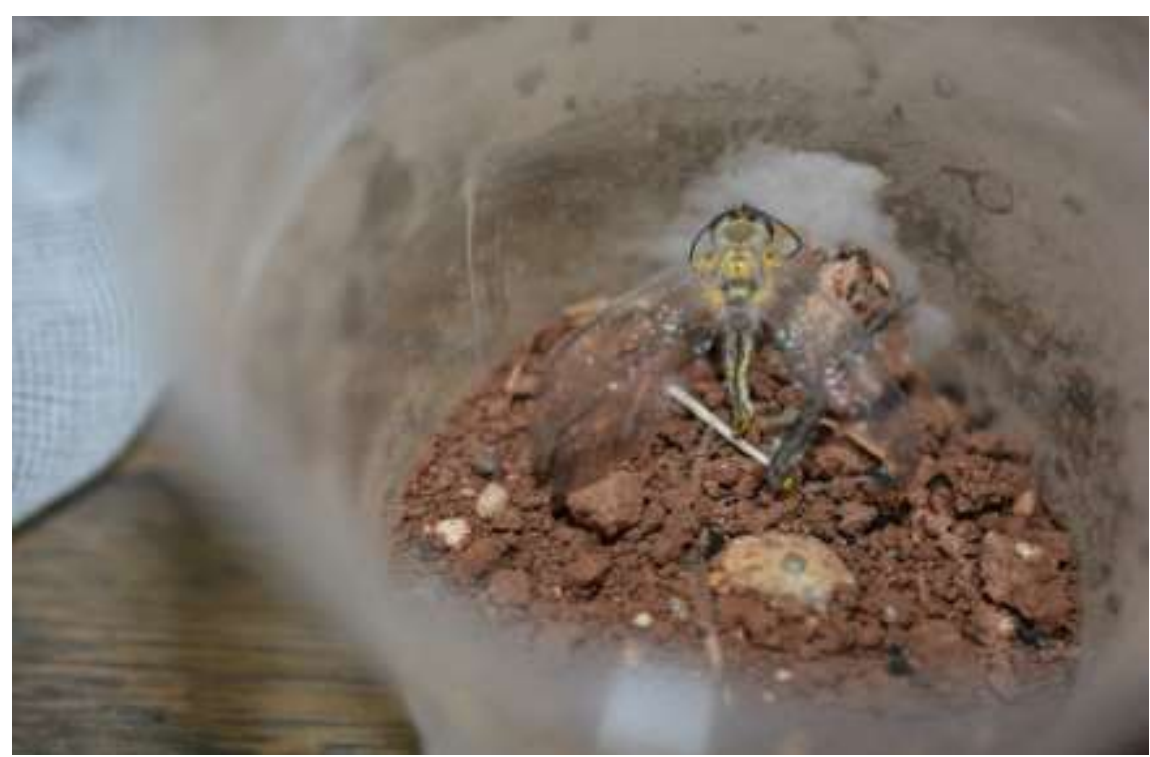

Şekil 2. Bubopsis hamata

Bubopsis andromache Aspöck ve ark., 1979

Tablo 2. Bubopsis andromache'nın çalışma alanındaki yayılışı ve yakalanan bireyler

\begin{tabular}{|c|c|c|c|c|}
\hline Kuzey & Doğu & Yükseklik(m) & Erkek & Dişi \\
\hline $38^{\circ} 29^{\prime} 50.40^{\prime \prime}$ & $39^{\circ} 30^{\prime} 25.66^{\prime \prime}$ & 1292 & 1 & 5 \\
\hline $38^{\circ} 29^{\prime} 46.74^{\prime \prime}$ & $39^{\circ} 30^{\prime} 29.02^{\prime \prime}$ & 1315 & - & 2 \\
\hline $38^{\circ} 29^{\prime} 45.82^{\prime \prime}$ & $39^{\circ} 30^{\prime} 29.11^{\prime \prime}$ & 1321 & 3 & 3 \\
\hline $38^{\circ} 29^{\prime} 7.52^{\prime \prime}$ & $39^{\circ} 20^{\prime} 27.23^{\prime \prime}$ & 1281 & - & 4 \\
\hline $38^{\circ} 29^{\prime} 7.42^{\prime \prime}$ & $39^{\circ} 20^{\prime} 26.99^{\prime \prime}$ & 1279 & 2 & - \\
\hline
\end{tabular}

*Bu tür Elâzığ ili için yeni kayıttır.

\section{Chrysopidae Schneider, 1851}

\section{Chrysopa Leach 1815}

Chrysopa dubitans McLachlan, 1887

Tablo 3. Chrysopa dubitans'nın çalışma alanındaki yayılışı ve yakalanan bireyler

\begin{tabular}{|c|c|c|c|c|}
\hline Kuzey & Doğu & Yükseklik(m) & Erkek & Dişi \\
\hline $38^{\circ} 29^{\prime} 41.01^{\prime \prime}$ & $39^{\circ} 30^{\prime} 0.98^{\prime \prime}$ & 1264 & 1 & - \\
\hline $38^{\circ} 29^{\prime} 42.10^{\prime \prime}$ & $39^{\circ} 30^{\prime} 1.70^{\prime \prime}$ & 1269 & - & 2 \\
\hline $38^{\circ} 29^{\prime} 38.12^{\prime \prime}$ & $39^{\circ} 30^{\prime} 0.29^{\prime \prime}$ & 1298 & 1 & - \\
\hline
\end{tabular}

*Bu tür Elâzığ ili için yeni kayıttır. 
Chrysoperla Steinmann, 1964

Chrysoperla carnea Stephen, 1836

Tablo 4. Chrysoperla carne'nın çalışma alanındaki yayılışı ve yakalanan bireyler

\begin{tabular}{|c|c|c|c|c|}
\hline Kuzey & Doğu & Yükseklik(m) & Erkek & Dişi \\
\hline $38^{\circ} 26^{\prime} 32.24^{\prime \prime}$ & $39^{\circ} 19^{\prime} 32.06^{\prime \prime}$ & 467 & 2 & - \\
\hline $38^{\circ} 26^{\prime} 41.33^{\prime \prime}$ & $39^{\circ} 18^{\prime} 49.09^{\prime \prime}$ & 389 & 1 & - \\
\hline $38^{\circ} 26^{\prime} 33.10^{\prime \prime}$ & $39^{\circ} 19^{\prime} 33.39^{\prime \prime}$ & 894 & - & 1 \\
\hline
\end{tabular}

Dichochrysa Yang, 1991

Dichochrysa flavifrons Brauer, 1850

Tablo 5. Dichochrysa flavifrons'nın çalışma alanındaki yayılışı ve yakalanan bireyler

\begin{tabular}{|c|c|c|c|c|}
\hline Kuzey & Dŏ̆u & Yükseklik(m) & Erkek & Dişi \\
\hline $38^{\circ} 29^{\prime} 55.19^{\prime \prime}$ & $39^{\circ} 22^{\prime} 27.14^{\prime \prime}$ & 1292 & 3 & 4 \\
\hline $38^{\circ} 29^{\prime} 56.72^{\prime \prime}$ & $39^{\circ} 22^{\prime} 30.06^{\prime \prime}$ & 1281 & 2 & 5 \\
\hline $38^{\circ} 29^{\prime} 56.63^{\prime \prime}$ & $39^{\circ} 22^{\prime} 28.90^{\prime \prime}$ & 1287 & 2 & - \\
\hline $38^{\circ} 29^{\prime} 10.70^{\prime \prime}$ & $39^{\circ} 28^{\prime} 30.12^{\prime \prime}$ & 1313 & 3 & 2 \\
\hline $38^{\circ} 29^{\prime} 11.30^{\prime \prime}$ & $39^{\circ} 28^{\prime} 32.72^{\prime \prime}$ & 1310 & 1 & 2 \\
\hline
\end{tabular}

Dichochrysa prasin Burmeister, 1839

Tablo 6.Dichochrysa prasina'nın çalışma alanındaki yayılışı ve yakalanan bireyler

\begin{tabular}{|c|c|c|c|c|}
\hline Kuzey & Doğu & Yükseklik(m) & Erkek & Dişi \\
\hline $38^{\circ} 27^{\prime} 50.28^{\prime \prime}$ & $39^{\circ} 24^{\prime} 14.69^{\prime \prime}$ & 1285 & 1 & 3 \\
\hline $38^{\circ} 27^{\prime} 51.16^{\prime \prime}$ & $39^{\circ} 24^{\prime} 15.15^{\prime \prime}$ & 1281 & - & 4 \\
\hline $38^{\circ} 27^{\prime} 50.40^{\prime \prime}$ & $39^{\circ} 24^{\prime} 16.09^{\prime \prime}$ & 1296 & 3 & 7 \\
\hline $38^{\circ} 28^{\prime} 11.10^{\prime \prime}$ & $39^{\circ} 25^{\prime} 44.12^{\prime \prime}$ & 1393 & 2 & 2 \\
\hline $38^{\circ} 29^{\prime} 11.75^{\prime \prime}$ & $39^{\circ} 28^{\prime} 33.31^{\prime \prime}$ & 1308 & 1 & 4 \\
\hline $38^{\circ} 29^{\prime} 11.74^{\prime \prime}$ & $39^{\circ} 28^{\prime} 35.98^{\prime \prime}$ & 1305 & - & 2 \\
\hline
\end{tabular}

Italochrysa Principi, 1946

Italochrysa italica Ross, 1790

Tablo 7. Italochrysa italica'nın çalışma alanındaki yayılışı ve yakalanan bireyler

\begin{tabular}{|c|c|c|c|c|}
\hline Kuzey & Doğu & Yükseklik(m) & Erkek & Dişi \\
\hline $38^{\circ} 29^{\prime} 13.51^{\prime \prime}$ & $39^{\circ} 28^{\prime} 32.40^{\prime \prime}$ & 1307 & 2 & 2 \\
\hline $38^{\circ} 29^{\prime} 9.95^{\prime \prime}$ & $39^{\circ} 28^{\prime} 29.19^{\prime \prime}$ & 1314 & 1 & 1 \\
\hline $38^{\circ} 28^{\prime} 13.32^{\prime \prime}$ & $39^{\circ} 25^{\prime} 46.42^{\prime \prime}$ & 1397 & - & 2 \\
\hline $38^{\circ} 28^{\prime} 11.40^{\prime \prime}$ & $39^{\circ} 25^{\prime} 45.51^{\prime \prime}$ & 1397 & 4 & - \\
\hline
\end{tabular}

*Bu tür Elâzığ ili için yeni kayıttır.

Hemerobiidae Latreille, 1803

Micromus Rambur, 1842

Wesmaelius (Kimminsia) subnebulosus Stephens, 1836

Tablo 8. Wesmaelius (Kimminsia) subnebulosus'un çalışma alanındaki yayılışı ve yakalanan bireyler

\begin{tabular}{|c|c|c|c|c|}
\hline Kuzey & Doğu & Yükseklik(m) & Erkek & Dişi \\
\hline $38^{\circ} 31^{\prime} 20.69^{\prime \prime}$ & $39^{\circ} 25^{\prime} 18.38^{\prime \prime}$ & 1270 & 2 & - \\
\hline $38^{\circ} 31^{\prime} 25.54^{\prime \prime}$ & $39^{\circ} 25^{\prime} 26.65^{\prime \prime}$ & 1273 & 1 & 3 \\
\hline $38^{\circ} 31^{\prime} 25.12^{\prime \prime}$ & $39^{\circ} 25^{\prime} 25.95^{\prime \prime}$ & 1272 & - & 2 \\
\hline $38^{\circ} 31^{\prime} 26.01^{\prime \prime}$ & $39^{\circ} 25^{\prime} 2.93^{\prime \prime}$ & 1314 & - & 1 \\
\hline $38^{\circ} 31^{\prime} 24.08^{\prime \prime}$ & $39^{\circ} 25^{\prime} 0.69^{\prime \prime}$ & 1297 & 1 & - \\
\hline $38^{\circ} 27^{\prime} 52.21^{\prime \prime}$ & $39^{\circ} 24^{\prime} 16.82^{\prime \prime}$ & 1285 & 1 & 1 \\
\hline
\end{tabular}




\section{Sympherobius Banks, 1904}

Sympherobius (Sympherobius) pygmaeus Rambur, 1842

Tablo 9. Sympherobius (Sympherobius) pygmaeus'un çalışma alanındaki yayılıșı ve yakalanan bireyler

\begin{tabular}{|c|c|c|c|c|}
\hline Kuzey & Doğu & Yükseklik(m) & Erkek & Dişi \\
\hline $38^{\circ} 29^{\prime} 3.63^{\prime \prime}$ & $39^{\circ} 28^{\prime} 12.21^{\prime \prime}$ & 1323 & 3 & 4 \\
\hline $38^{\circ} 29^{\prime} 3.53^{\prime \prime}$ & $39^{\circ} 28^{\prime} 11.45^{\prime \prime}$ & 1322 & 2 & - \\
\hline $38^{\circ} 29^{\prime} 3.04^{\prime \prime}$ & $39^{\circ} 28^{\prime} 13.33^{\prime \prime}$ & 1325 & 1 & 2 \\
\hline
\end{tabular}

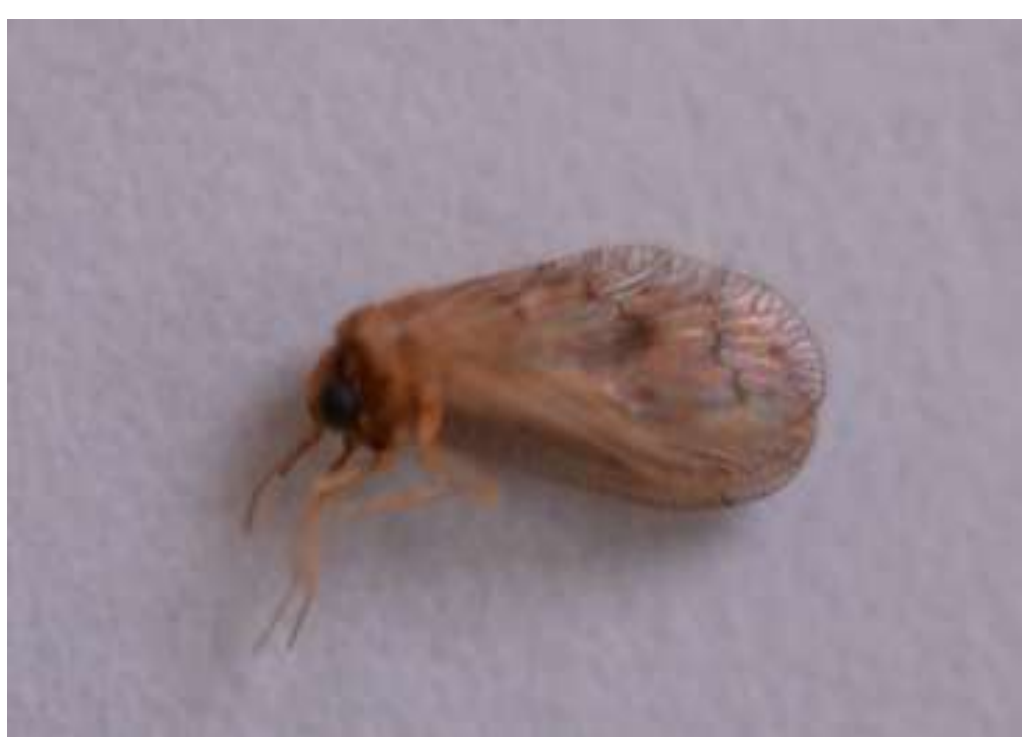

Şekil 3. Sympherobius (Sympherobius) pygmaeus

Myrmeleontidae Latreille, 1803

Palpares Rambur, 1842

Palpares libelluloides Linnaeus, 1764

Tablo 10. Palpares libelluloides'in çalışma alanındaki yayılışı ve yakalanan bireyler

\begin{tabular}{|c|c|c|c|c|}
\hline Kuzey & Doğu & Yükseklik(m) & Erkek & Dişi \\
\hline $38^{\circ} 28^{\prime} 49.10^{\prime \prime}$ & $39^{\circ} 31^{\prime} 17.45^{\prime \prime}$ & 1288 & 1 & - \\
\hline $38^{\circ} 28^{\prime} 49.80^{\prime \prime}$ & $39^{\circ} 31^{\prime} 17.91^{\prime \prime}$ & 1283 & 1 & - \\
\hline $38^{\circ} 28^{\prime} 49.66^{\prime \prime}$ & $39^{\circ} 31^{\prime} 18.04^{\prime \prime}$ & 1283 & 2 & 4 \\
\hline $38^{\circ} 31^{\prime} 29.28^{\prime \prime}$ & $39^{\circ} 24^{\prime} 58.38^{\prime \prime}$ & 1301 & 3 & 2 \\
\hline $38^{\circ} 31^{\prime} 28.92^{\prime \prime}$ & $39^{\circ} 24^{\prime} 57.57^{\prime \prime}$ & 1298 & - & 1 \\
\hline $38^{\circ} 31^{\prime} 23.97^{\prime \prime}$ & $39^{\circ} 25^{\prime} 2.18^{\prime \prime}$ & 1300 & 1 & - \\
\hline
\end{tabular}

Euroleon Esben-Petersen, 1918

Euroleon nostras Geoffroy in fourcroy, 1785

Tablo 11. Euroleon nostras'ın çalıșma alanındaki yayılıșı ve yakalanan bireyler

\begin{tabular}{|c|c|c|c|c|}
\hline Kuzey & Doğu & Yükseklik(m) & Erkek & Dişi \\
\hline $38^{\circ} 31^{\prime} 25.37^{\prime \prime}$ & $39^{\circ} 25^{\prime} 26.39^{\prime \prime}$ & 1273 & 1 & - \\
\hline $38^{\circ} 31^{\prime} 34.91^{\prime \prime}$ & $39^{\circ} 25^{\prime} 59.60^{\prime \prime}$ & 1281 & 3 & - \\
\hline $38^{\circ} 28^{\prime} 50.02^{\prime \prime}$ & $39^{\circ} 31^{\prime} 17.84^{\prime \prime}$ & 1283 & - & 2 \\
\hline $38^{\circ} 30^{\prime} 17.79^{\prime \prime}$ & $39^{\circ} 30^{\prime} 48.56^{\prime \prime}$ & 1315 & 1 & - \\
\hline $38^{\circ} 31^{\prime} 27.50^{\prime \prime}$ & $39^{\circ} 29^{\prime} 17.14^{\prime \prime}$ & 1294 & 1 & 2 \\
\hline $38^{\circ} 31^{\prime} 35.01^{\prime \prime}$ & $39^{\circ} 28^{\prime} 31.43^{\prime \prime}$ & 1266 & 1 & 1 \\
\hline
\end{tabular}

*Bu tür Elâzığ ili için yeni kayıttır. 
Myrmeleon Linnaeus, 1767

Myrmeleon inconspicuus Rambur 1842

Tablo 12. Myrmeleon inconspicuus'un çalışma alanındaki yayılışı ve yakalanan bireyler

\begin{tabular}{|c|c|c|c|c|}
\hline Kuzey & Doğu & Yükseklik(m) & Erkek & Dişi \\
\hline $38^{\circ} 31^{\prime} 21.58^{\prime \prime}$ & $39^{\circ} 25^{\prime} 18.81^{\prime \prime}$ & 1274 & 2 & 3 \\
\hline $38^{\circ} 31^{\prime} 21.38^{\prime \prime}$ & $39^{\circ} 25^{\prime} 18.56^{\prime \prime}$ & 1274 & 1 & - \\
\hline $38^{\circ} 31^{\prime} 21.08^{\prime \prime}$ & $39^{\circ} 25^{\prime} 18.68^{\prime \prime}$ & 1271 & 1 & - \\
\hline $38^{\circ} 30^{\prime} 14.50^{\prime \prime}$ & $39^{\circ} 30^{\prime} 46.60^{\prime \prime}$ & 1321 & - & 1 \\
\hline $38^{\circ} 30^{\prime} 12.92^{\prime \prime}$ & $39^{\circ} 30^{\prime} 45.66^{\prime \prime}$ & 1316 & - & 2 \\
\hline $38^{\circ} 30^{\prime} 13.17^{\prime \prime}$ & $39^{\circ} 30^{\prime} 43.73^{\prime \prime}$ & 1311 & - & 2 \\
\hline
\end{tabular}

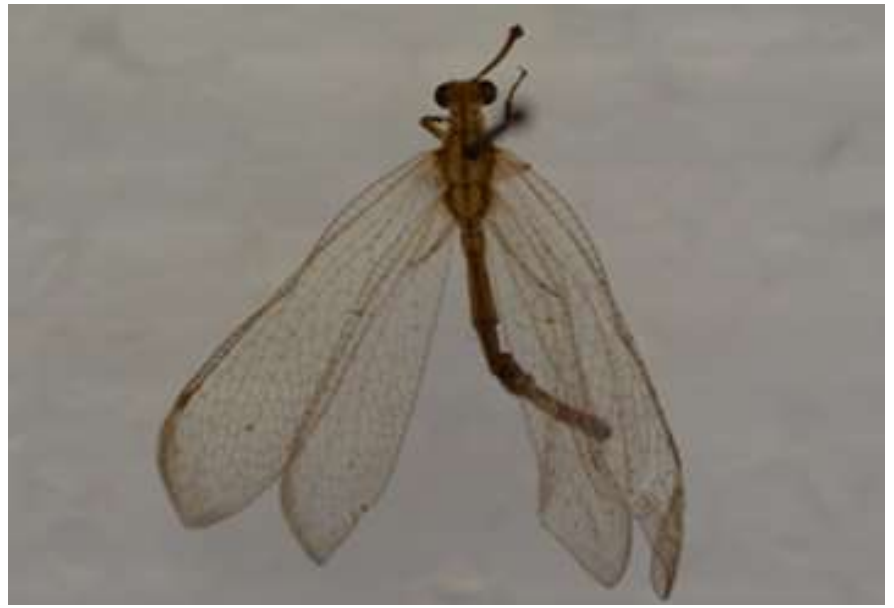

Şekil 4. Myrmeleon inconspicuus

\section{Cueta Navas, 1911}

\section{Cueta lineosa Rambur, 1842}

Tablo 13. Cueta lineosa'nın çalışma alanındaki yayılışı ve yakalanan bireyler

\begin{tabular}{|c|c|c|c|c|}
\hline Kuzey & Dŏ̆u & Yükseklik(m) & Erkek & Dişi \\
\hline $38^{\circ} 26^{\prime} 55.70^{\prime \prime}$ & $39^{\circ} 21^{\prime} 18.41^{\prime \prime}$ & 1264 & 1 & - \\
\hline $38^{\circ} 26^{\prime} 31.17^{\prime \prime}$ & $39^{\circ} 20^{\prime} 1.06^{\prime \prime}$ & 1263 & 2 & 1 \\
\hline $38^{\circ} 30^{\prime} 21.38^{\prime \prime}$ & $39^{\circ} 23^{\prime} 43.53^{\prime \prime}$ & 1305 & 1 & - \\
\hline $38^{\circ} 30^{\prime} 15.97^{\prime \prime}$ & $39^{\circ} 30^{\prime} 43.06^{\prime \prime}$ & 1316 & 2 & 2 \\
\hline $38^{\circ} 30^{\prime} 15.32^{\prime \prime}$ & $39^{\circ} 30^{\prime} 47.90^{\prime \prime}$ & 1322 & 1 & - \\
\hline $38^{\circ} 30^{\prime} 19.45^{\prime \prime}$ & $39^{\circ} 23^{\prime} 36.47^{\prime \prime}$ & 1286 & - & 1 \\
\hline $38^{\circ} 30^{\prime} 18.31^{\prime \prime}$ & $39^{\circ} 23^{\prime} 43.72^{\prime \prime}$ & 1284 & 1 & - \\
\hline
\end{tabular}

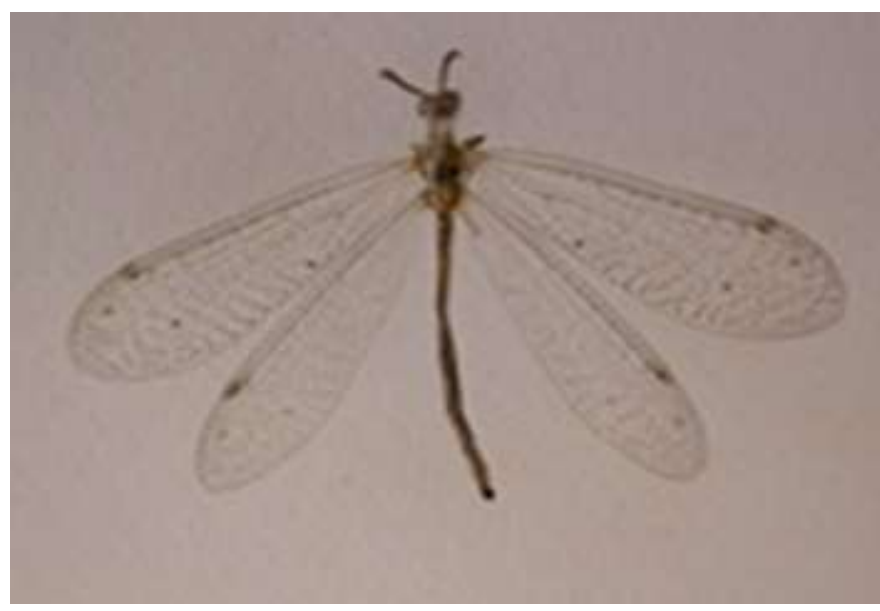

Şekil 5. Cueta lineosa 
Solter Navas, 1902

Solter ledereri Navas, 1912

Tablo 14. Solter ledereri'nin çalışma alanındaki yayılışı ve yakalanan bireyler

\begin{tabular}{|c|c|c|c|c|}
\hline Kuzey & Doğu & Yükseklik(m) & Erkek & Dişi \\
\hline $38^{\circ} 26^{\prime} 31.27^{\prime \prime}$ & $39^{\circ} 20^{\prime} 0.36^{\prime \prime}$ & 1262 & 1 & - \\
\hline $38^{\circ} 26^{\prime} 30.17^{\prime \prime}$ & $39^{\circ} 19^{\prime} 54.78^{\prime \prime}$ & 1263 & - & 1 \\
\hline $38^{\circ} 29^{\prime} 56.18^{\prime \prime}$ & $39^{\circ} 22^{\prime} 34.24^{\prime \prime}$ & 1279 & 1 & 2 \\
\hline $38^{\circ} 30^{\prime} 16.55^{\prime \prime}$ & $39^{\circ} 23^{\prime} 34.83^{\prime \prime}$ & 1277 & 1 & 2 \\
\hline $38^{\circ} 30^{\prime} 16.39^{\prime \prime}$ & $39^{\circ} 23^{\prime} 31.59^{\prime \prime}$ & 1300 & 1 & 3 \\
\hline
\end{tabular}

*Bu tür Elâzığ ili için yeni kayıttır.

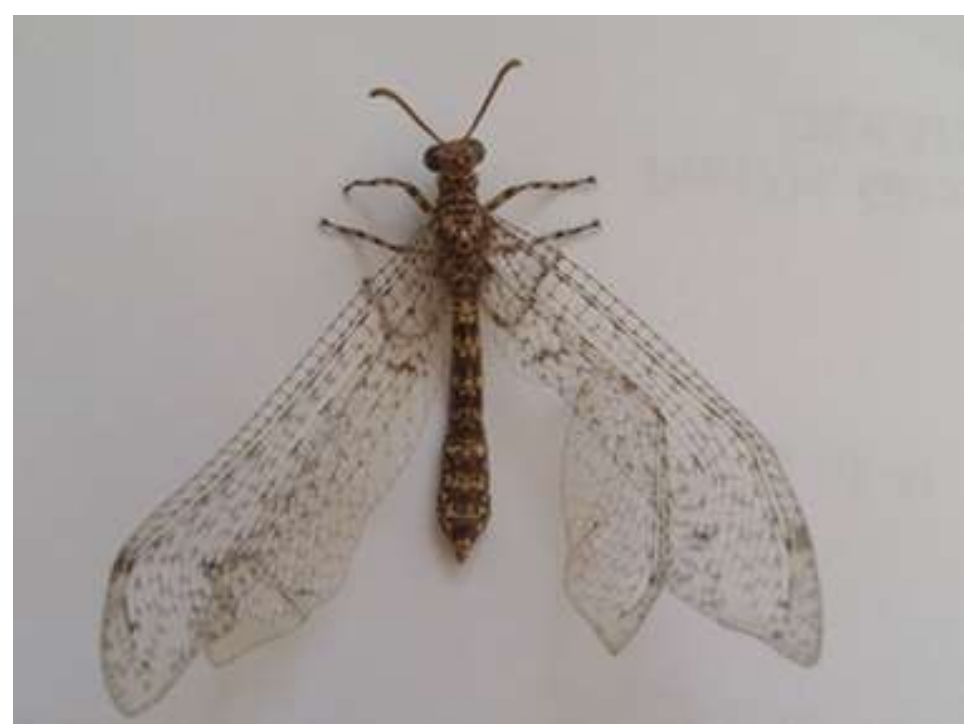

Şekil 6. Solter ledereri

\section{Creoleon Tillyard, 1918}

\section{Creoleon plumbeus Olivier, 1811}

Tablo 15. Creoleon plumbeus' in çalıșma alanındaki yayılıșı ve yakalanan bireyler

\begin{tabular}{|c|c|c|c|c|}
\hline Kuzey & Doğu & Yükseklik(m) & Erkek & Dişi \\
\hline $38^{\circ} 28^{\prime} 48.96^{\prime \prime}$ & $39^{\circ} 31^{\prime} 15.76^{\prime \prime}$ & 1298 & - & 4 \\
\hline $38^{\circ} 28^{\prime} 48.92^{\prime \prime}$ & $39^{\circ} 31^{\prime} 16.05^{\prime \prime}$ & 1296 & 1 & 3 \\
\hline $38^{\circ} 28^{\prime} 49.17^{\prime \prime}$ & $39^{\circ} 31^{\prime} 15.28^{\prime \prime}$ & 1299 & 2 & - \\
\hline $38^{\circ} 30^{\prime} 33.39^{\prime \prime}$ & $39^{\circ} 30^{\prime} 32.58^{\prime \prime}$ & 1288 & - & 2 \\
\hline
\end{tabular}

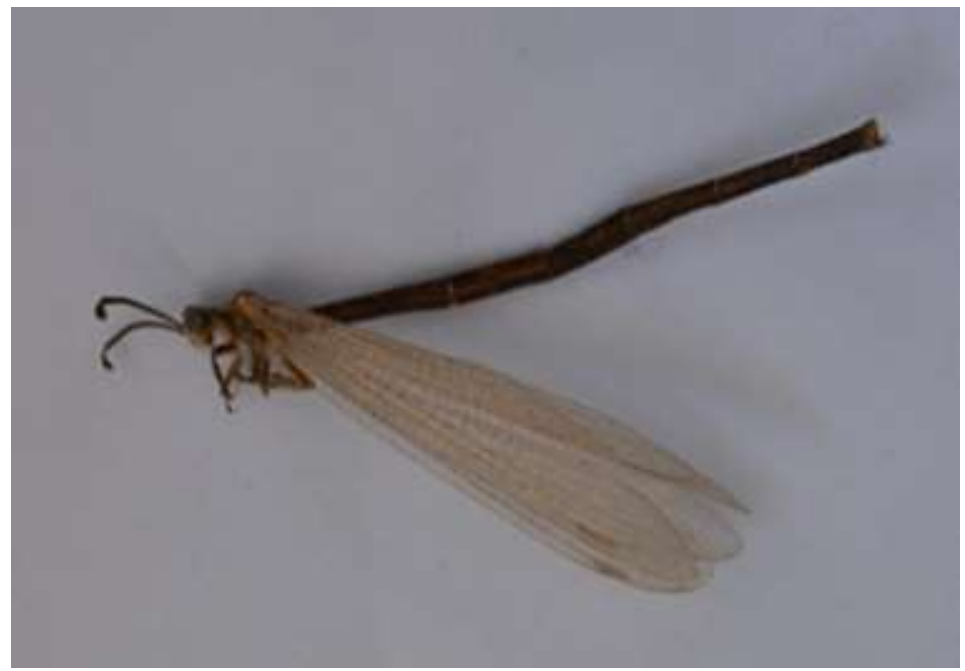

Şekil 7. Creoleon plumbeus 
Distoleon Banks, 1910

Distoleon tetragrammicus Fabricius, 1798

Tablo 15. Distoleon tetragrammicus'un çalışma alanındaki yayılışı ve yakalanan bireyler

\begin{tabular}{|c|c|c|c|c|}
\hline Kuzey & Doğu & Yükseklik(m) & Erkek & Dişi \\
\hline $38^{\circ} 28^{\prime} 49.29^{\prime \prime}$ & $39^{\circ} 31^{\prime} 16.24^{\prime \prime}$ & 1294 & 1 & - \\
\hline $38^{\circ} 30^{\prime} 34.39^{\prime \prime}$ & $39^{\circ} 30^{\prime} 36.04^{\prime \prime}$ & 1293 & 1 & - \\
\hline $38^{\circ} 30^{\prime} 33.40^{\prime \prime}$ & $39^{\circ} 30^{\prime} 36.56^{\prime \prime}$ & 1300 & - & 2 \\
\hline $38^{\circ} 29^{\prime} 47.02^{\prime \prime}$ & $39^{\circ} 30^{\prime} 25.02^{\prime \prime}$ & 1303 & 2 & - \\
\hline $38^{\circ} 29^{\prime} 52.18^{\prime \prime}$ & $39^{\circ} 22^{\prime} 27.45^{\prime \prime}$ & 1281 & 3 & - \\
\hline $38^{\circ} 29^{\prime} 54.75^{\prime \prime}$ & $39^{\circ} 22^{\prime} 29.84^{\prime \prime}$ & 1277 & 1 & 3 \\
\hline
\end{tabular}

*Bu tür Elâzığ ili için yeni kayıttır.

\section{Distoleon curdicus Hölzel, 1972}

Tablo 16. Distoleon curdicus'un çalışma alanındaki yayılışı ve yakalanan bireyler

\begin{tabular}{|c|c|c|c|c|}
\hline Kuzey & Doğu & Yükseklik(m) & Erkek & Dişi \\
\hline $38^{\circ} 27^{\prime} 38.71^{\prime \prime}$ & $39^{\circ} 23^{\prime} 36.88^{\prime \prime}$ & 1303 & 1 & 3 \\
\hline $38^{\circ} 27^{\prime} 40.24^{\prime \prime}$ & $39^{\circ} 23^{\prime} 37.72^{\prime \prime}$ & 1292 & 1 & - \\
\hline $38^{\circ} 27^{\prime} 43.30^{\prime \prime}$ & $39^{\circ} 23^{\prime} 34.01^{\prime \prime}$ & 1272 & - & 4 \\
\hline $38^{\circ} 27^{\prime} 28.74^{\prime \prime}$ & $39^{\circ} 23^{\prime} 1.36^{\prime \prime}$ & 1269 & 2 & - \\
\hline
\end{tabular}

Neuroleon Navas, 1909

Neuroleon egenus Navas, 1915

Tablo 17. Neuroleon egenus'un çalışma alanındaki yayılışı ve yakalanan bireyler

\begin{tabular}{|c|c|c|c|c|}
\hline Kuzey & Doğu & Yükseklik(m) & Erkek & Dişi \\
\hline $38^{\circ} 28^{\prime} 36.00^{\prime \prime}$ & $39^{\circ} 27^{\prime} 18.49^{\prime \prime}$ & 1389 & 1 & - \\
\hline $38^{\circ} 28^{\prime} 37.40^{\prime \prime}$ & $39^{\circ} 27^{\prime} 18.72^{\prime \prime}$ & 1376 & - & 2 \\
\hline $38^{\circ} 28^{\prime} 37.72^{\prime \prime}$ & $39^{\circ} 27^{\prime} 19.15^{\prime \prime}$ & 1376 & - & 3 \\
\hline $38^{\circ} 28^{\prime} 39.58^{\prime \prime}$ & $39^{\circ} 27^{\prime} 12.69^{\prime \prime}$ & 1327 & 2 & 2 \\
\hline
\end{tabular}

*Bu tür Elâzığ ili için yeni kayıttır.

\section{Myrmecaelurus Costa, 1855}

Myrmecaelurus trigrammus Pallas, 1771

Tablo 18. Myrmecaelurus trigrammus'un çalışma alanındaki yayılışı ve yakalanan bireyler

\begin{tabular}{|c|c|c|c|c|}
\hline Kuzey & Doğu & Yükseklik(m) & Erkek & Dişi \\
\hline $38^{\circ} 28^{\prime} 58.12^{\prime \prime}$ & $39^{\circ} 27^{\prime} 37.89^{\prime \prime}$ & 1262 & 1 & 3 \\
\hline $38^{\circ} 28^{\prime} 59.22^{\prime \prime}$ & $39^{\circ} 27^{\prime} 36.53^{\prime \prime}$ & 1260 & 2 & 5 \\
\hline $38^{\circ} 28^{\prime} 58.19^{\prime \prime}$ & $39^{\circ} 27^{\prime} 35.55^{\prime \prime}$ & 1264 & 1 & 2 \\
\hline
\end{tabular}

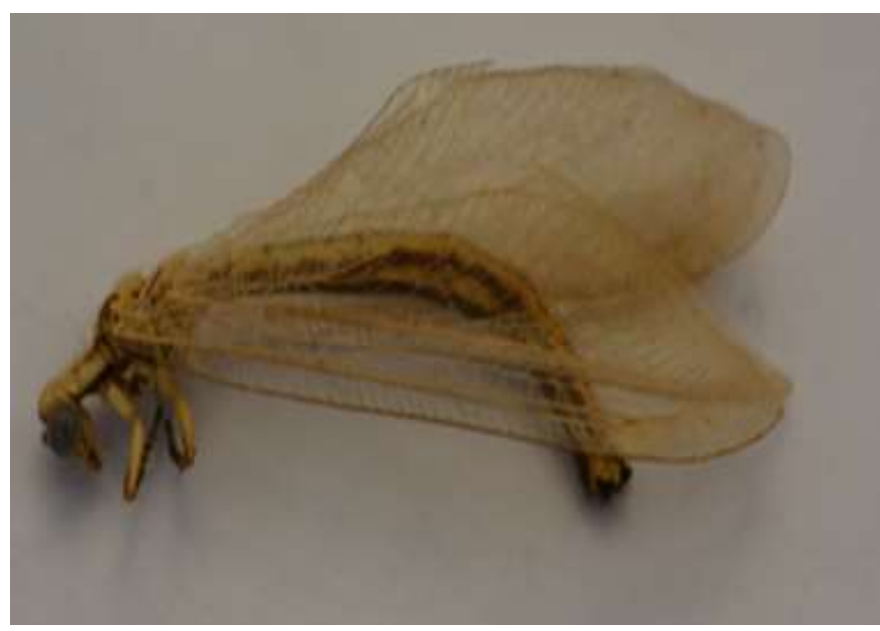

Şekil 8. Myrmecaelurus trigrammus 


\section{Myrmecaelurus majör McLachan, 1875}

Tablo 19. Myrmecaelurus majör' 'ün çalışma alanındaki yayılışı ve yakalanan bireyler

\begin{tabular}{|c|c|c|c|c|}
\hline Kuzey & Doğu & Yükseklik(m) & Erkek & Dissi \\
\hline $38^{\circ} 27^{\prime} 30.41^{\prime \prime}$ & $39^{\circ} 22^{\prime} 58.94^{\prime \prime}$ & 1259 & 1 & 1 \\
\hline $38^{\circ} 27^{\prime} 27.07^{\prime \prime}$ & $39^{\circ} 22^{\prime} 57.75^{\prime \prime}$ & 1275 & 2 & - \\
\hline $38^{\circ} 27^{\prime} 29.19^{\prime \prime}$ & $39^{\circ} 22^{\prime} 57.75^{\prime \prime}$ & 1263 & 1 & 6 \\
\hline $38^{\circ} 27^{\prime} 27.10^{\prime \prime}$ & $39^{\circ} 22^{\prime} 55.60^{\prime \prime}$ & 1273 & - & 1 \\
\hline
\end{tabular}

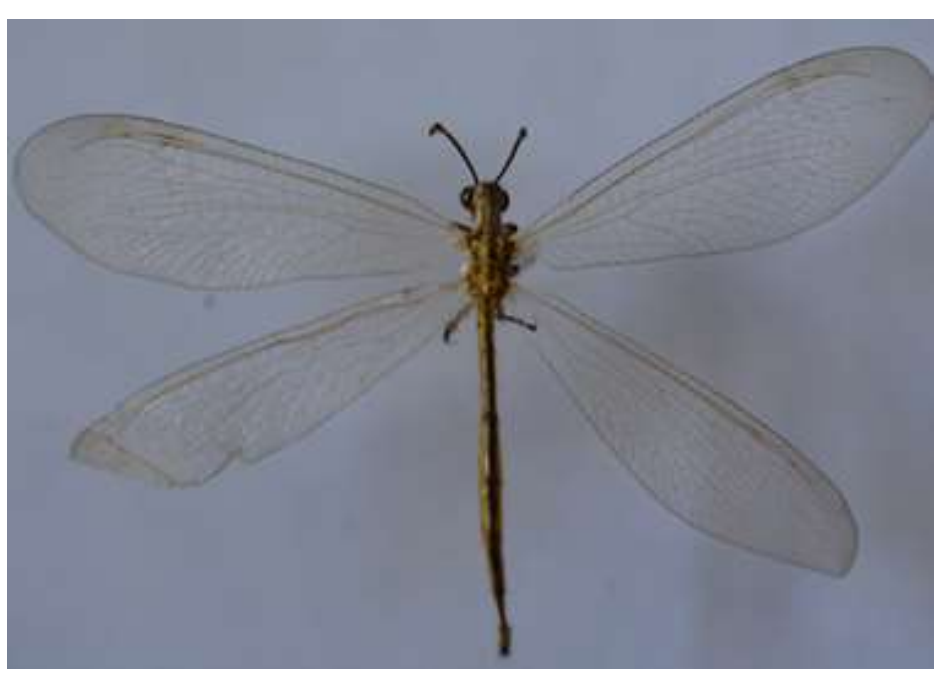

Şekil 9. Myrmecaelurus majör

Nemopteridae Burmeister, 1839

Nemoptera Latreille, 1802

Nemoptera sinuata Olivier, 1811

Tablo 20. Nemoptera sinuata'nın çalışma alanındaki yayılışı ve yakalanan bireyler

\begin{tabular}{|c|c|c|c|c|}
\hline Kuzey & Doğu & Yükseklik(m) & Erkek & Dişi \\
\hline $38^{\circ} 26^{\prime} 58.40^{\prime \prime}$ & $39^{\circ} 21^{\prime} 22.91^{\prime \prime}$ & 1262 & 1 & 1 \\
\hline $38^{\circ} 26^{\prime} 56.77^{\prime \prime}$ & $39^{\circ} 21^{\prime} 21.71^{\prime \prime}$ & 1267 & 1 & - \\
\hline $38^{\circ} 26^{\prime} 55.15^{\prime \prime}$ & $39^{\circ} 21^{\prime} 18.84^{\prime \prime}$ & 1268 & 1 & 6 \\
\hline $38^{\circ} 26^{\prime} 31.23^{\prime \prime}$ & $39^{\circ} 20^{\prime} 0.74^{\prime \prime}$ & 1262 & 2 & - \\
\hline
\end{tabular}

*Bu tür Elâzığ ili için yeni kayıttır.

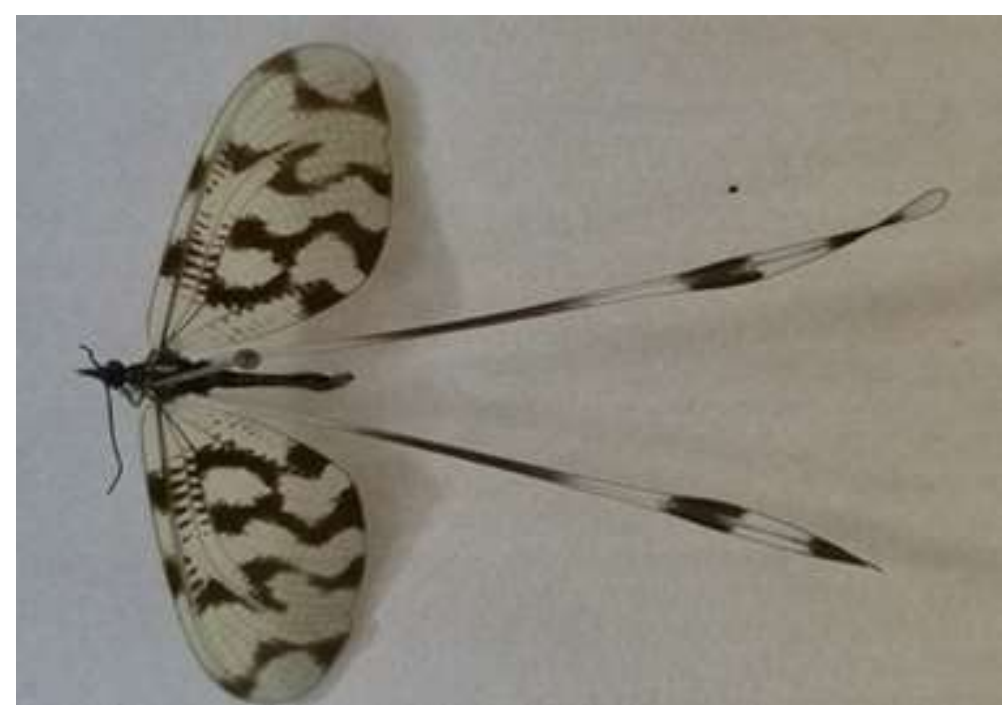

Şekil 10. Nemoptera sinuata 


\section{Lertha Navas, 1910}

Lertha extensa Oliver, 1811

Tablo 21. Lertha extensa'nın çalışma alanındaki yayılışı ve yakalanan bireyler

\begin{tabular}{|c|c|c|c|c|}
\hline Kuzey & Doğu & Yükseklik(m) & Erkek & Dişi \\
\hline $38^{\circ} 28^{\prime} 37.77^{\prime \prime}$ & $39^{\circ} 27^{\prime} 10.81^{\prime \prime}$ & 1346 & 1 & 1 \\
\hline $38^{\circ} 28^{\prime} 36.15^{\prime \prime}$ & $39^{\circ} 27^{\prime} 10.30^{\prime \prime}$ & 1368 & 3 & - \\
\hline $38^{\circ} 28^{\prime} 32.09^{\prime \prime}$ & $39^{\circ} 18^{\prime} 14.25^{\prime \prime}$ & 1268 & - & 4 \\
\hline $38^{\circ} 28^{\prime} 31.58^{\prime \prime}$ & $39^{\circ} 18^{\prime} 12.15^{\prime \prime}$ & 1265 & 3 & - \\
\hline
\end{tabular}

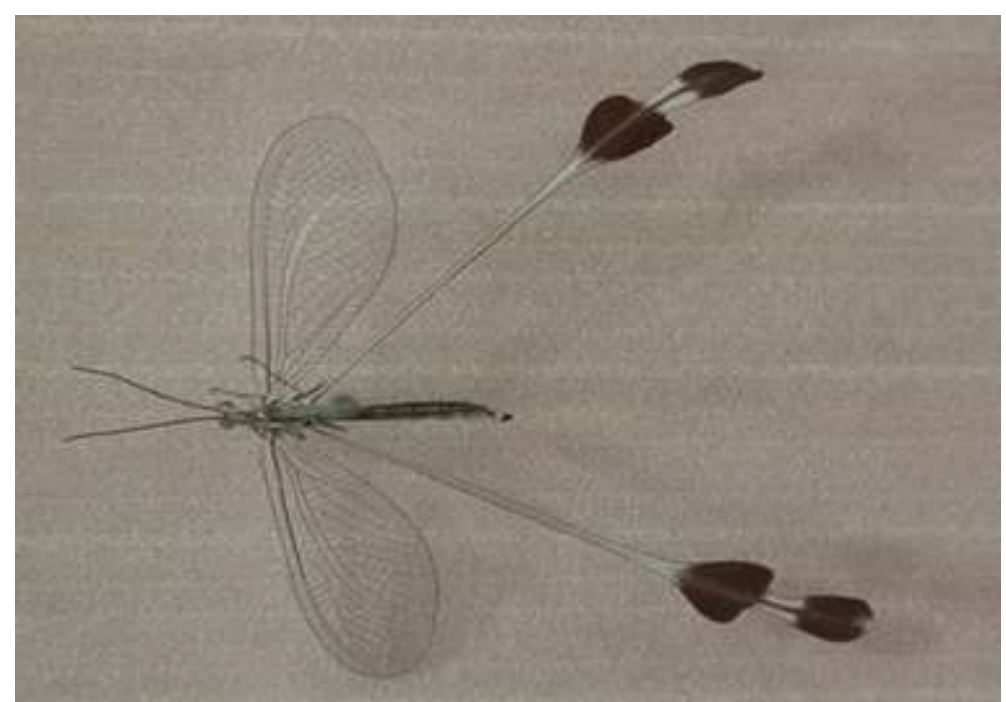

Şekil 11. Lertha extensa

\section{Lertha sheppardi Oliver, 1904}

Tablo 22. Lertha sheppardi'nin çalışma alanındaki yayılışı ve yakalanan bireyler

\begin{tabular}{|c|c|c|c|c|}
\hline Kuzey & Doğu & Yükseklik(m) & Erkek & Dişi \\
\hline $38^{\circ} 27^{\prime} 51.81^{\prime \prime}$ & $39^{\circ} 24^{\prime} 15.71^{\prime \prime}$ & 1280 & 4 & - \\
\hline $38^{\circ} 28^{\prime} 12.26^{\prime \prime}$ & $39^{\circ} 25^{\prime} 47.10^{\prime \prime}$ & 1400 & 1 & - \\
\hline $38^{\circ} 28^{\prime} 12.68^{\prime \prime}$ & $39^{\circ} 25^{\prime} 45.37^{\prime \prime}$ & 1394 & 2 & 4 \\
\hline $38^{\circ} 28^{\prime} 12.12^{\prime \prime}$ & $39^{\circ} 25^{\prime} 44.71^{\prime \prime}$ & 1393 & - & 1 \\
\hline
\end{tabular}

*Bu tür Elâzığ ili için yeni kayıttır.

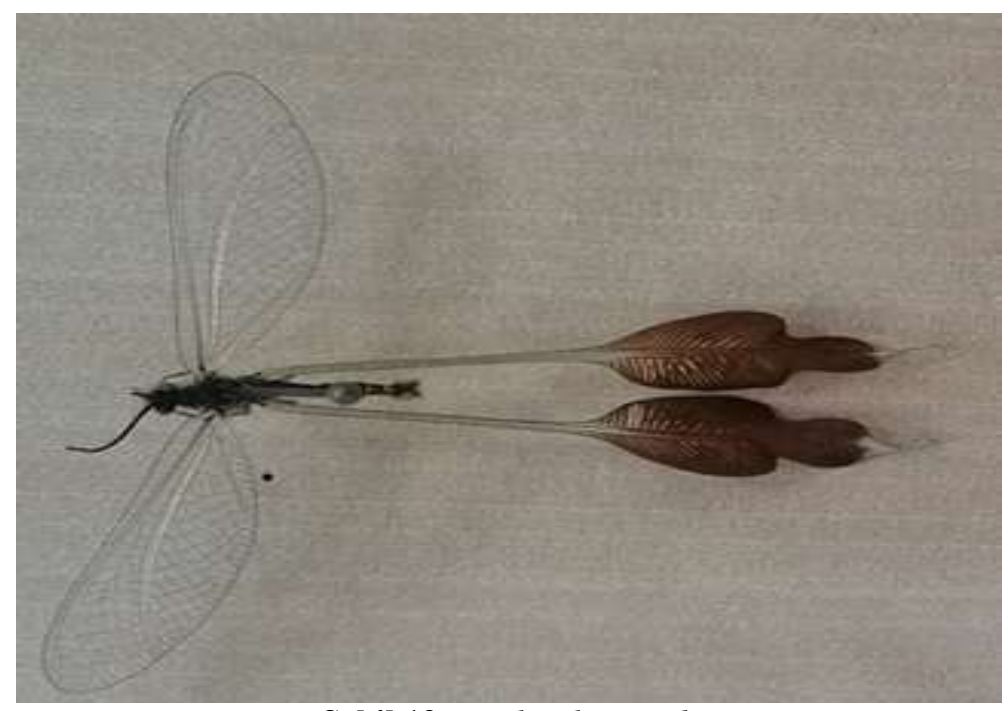

Şekil 12. Lertha sheppardi 


\section{Sonuç ve Öneriler}

Günümüze kadar yapılan çalışmalardan Özbay ve arkadaşlarının [16] yaptı̆̆ 1 "Elâzığ ilinin Neuroptera faunasının saptanması" adlı çalışmada 7 familyaya ait 19 tür ve Arı'nın [12] Türkiye Neuroptera faunasının Cheklisti'nde ise Elâzığ iline ait 5 familyaya ait 20 tür belirlenmiştir. Bunlara ilave olarak da 10 tür bu çalışmada saptanmış olup ildeki tür sayısı 30'a yükselmiştir. Daha önceden tespit edilen Chrysopidae familyasindan Cunctochrysa albolineata (Killington, 1935) ve Pseudomallada clathratus (Schneider, 1845) Hölzel tarafindan [18], Suarius nanus (McLachlan, 1893) Şengonca tarafindan [19] Elâzığ ili için kayıt edilmişlerdir. Fakat Elâzığ' da yapılan güncel kaynaklarda ve yapılan bu araştırmada bu türlere rastlanılmamıştır. Bu araştırmamızda önceden saptanan örneklere rastlanılmama nedeni olarak çalışma bölgemiz olan Hazar Gölünün Elâzığ ilinin sadece bir bölümünü içerdiğinden ve kıyı bölgelerin turistik olarak yerleşime açılmasına bağlıyoruz. Daha kapsamlı çalışmalarla İldeki Neuroptera türü sayısının artacağı düşünülmektedir.

\section{Teşekkür}

Nalan KOYUNCU'nun yüksek lisans tezinin bir bölümü olan bu çalışmayı ZGEF.17.025 nolu projeyle destekleyen Dicle Üniversitesi Bilimsel Araştırma Proje Koordinatörlügüne teşekkür ederiz.

\section{Yazarların Katkısı}

İlk yazar \%60, ikinci yazar \%40 oranında katkıda bulunmuştur.

\section{Çıkar Çatışması Beyanı}

Yazarlar arasında herhangi bir çıkar çatışması bulunmamaktadır.

\section{Araştırma ve Yayın Etiği Beyanı}

Yapılan çalışmada araştırma ve yayın etiğine uyulmuştur.

\section{Kaynaklar}

[1] Carpenter F.M. 1943. Part 9. The Orders Neuroptera, Raphidiodea, Caloneurodea and Protorthoptera (Probnisidae), with additional Protodonata and Megasecoptera. The Lower Permian Insects of Kansas. Proceedings of the American Academy of Arts and Sciences, 75: 5584.

[2] Aspöck H., Aspöck U., Hölzel H. 1980. Eine zusammenfassende Darstellung der Systematik, Ökologie und Chorologie der Neuropteroidea (Megaloptera, Raphidioptera, Planipennia) Europas. Die Neuropteren Europas. Goecke\&Evers, 1: 1-495, 2: 1-355.

[3] Şengonca Ç. 1980. Türkiye Chrysopidae (Neuroptera) Faunası Üzerine Sistematik ve Taksonomik Araştırmalar. I. Familyanın Genel Tanımı. Türk. Bit. Kor. Derg., 5 (2): 91-99.

[4] Stelzl M., Devetak D. 1999. Neuroptera in agricultural ecosystems. Agriculture Ecosystems and Environment, 74: 305-321.

[5] Gepp J. 1969. Eine neue Coniopterygiden Art aus Anatolien: Aleuropteryx perpusilla n. sp. (Neuroptera, Planipennia). Zeitschrift der Arbeitsgemeinschaft Österreichischer Entomologen, 21: $12-15$.

[6] Koçak A.Ö. 1976. A new subspecies of Myrmeleonidae (Neuroptera) from Turkey, Nachrichtenblatt der Bayerischen Entomologen, 25: 97-100.

[7] Şengonca, Ç. 1979. Beitrag zur Neuropteren fauna der Türkei. Nachrichtenblatt der Bayerischen Entomologen, 28 (1): 10-15.

[8] Onar N. 1997. Edirne Yöresi Chrysopidae (Raphidiidae; Neuroptera) faunas1 üzerine türlerin taksonomik ve faunistik yönden araştırılması. Türk Entomoloji Dergisi, 26 (2): 121-134. 
[9] Canbulat S. 1998. Çanakkale Planipennia (Insecta: Neuropteroidea) Türlerinin Sistematik ve Faunistik Yönden İncelenmesi. Yüksek Lisans Tezi, Gazi Üniversitesi Fen Bilimleri Enstitüsü, Ankara.

[10] Ar1 İ., Kiyak S. 2000. New and Additional Distributional and Faunistic Data of Turkish Planipennia. Journal of Entomological Research Society, 2 (1): 9-15.

[11] Satar A. 2002. Güney Doğu Anadolu Bölgesi (Neuroptera: Insecta) Faunasının Saptanması. Doktora Tezi, Dicle Üniversitesi, Fen Bilimleri Enstitüsü, Diyarbakır.

[12] Ar1 I. 2014. A checklist of Turkish neuropteran species (Insecta: Neuroptera) with remarks on provincial distribution in Turkey. Acta entomologica slovenica, 22 (1): 59-86.

[13] Arı İ., Aktaş M., Kıyak S. 2007. Notes on the Chrysopidae (Neuroptera) Fauna of Ardahan, Iğdır and Kars Provinces of Turkey. Turkish Journal of Zoology, 31: 201-208.

[14] Onar N. 2007. Trakya Bölgesi Neuroptera Faunas1 Üzerine Taksonomik ve Faunistik Araştırmalar. Doktora Tezi, Trakya Üniversitesi, Fen Bilimleri Enstitüsü, Edirne.

[15] Dobosz R., Ábrahám L. 2009. Contribution to the knowledge of the Turkish tail-wings (Neuroptera:Nemopteridae). Natura Somogyiensis, 15: 113-126.

[16] Özbay C., Satar A., Akkaya A. 2005. Neuroptera Fauna of Elâzı̆̆ Province (Turkey). Boletin Sociedad Entomologica Aragoesa, 36: 302.

[17] Aspöck H., Hölzel H., Aspöck U. 2001. Denisia 2. Kommentierter katalog der Neuropterida (Insecta: Raphidioptera, Megaloptera, Neuroptera) der Westpaläarktis. Landes museum, 1-612.

[18] Hölzel H. 1967. Chrysopiden aus der Mongolei. Ergebnisse der Mongolisch Deutschen Biologischen Expeditionen seit 1962, Nr. 31. Mitteilungen aus dem Zoologischen Museum in Berlin, 43: 251-260.

[19] Şengonca Ç. 1981. Türkiye Nemopteridae (Insecta: Neuroptera) Faunası Üzerine Taksonomik Araştırmalar. II. Faunistik. Türk. Bit. Kor. Derg., 5 (2): 101-114. 